\title{
A dinâmica do conhecimento biomédico e em saúde: uma interpretação sociológica
}

\author{
Maria Conceição da Costa* \\ Renan Gonçalves Leonel da Silva**
}

\section{Resumo}

A produção de conhecimento biomédico e em saúde tem crescido como objeto de pesquisa das Ciências Sociais. Mudanças cientificas e tecnológicas, assim como a emergência de novos arranjos sociais na maneira de fazer pesquisa e na elaboração das agendas, produziram esse interesse. O objetivo deste ensaio é apresentar algumas características centrais desse tema como objeto de pesquisa sociológica, para o qual destacamos três eixos de análise imbricados entre si, relativos às transformações na área médica e da saúde, no padrão de financiamento à pesquisa e à sua plataforma tecnológica. Com isso, o texto fornece algumas ferramentas para se avançar na pesquisa, do ponto de vista dos estudos sociais da ciência e da sociologia da produção do conhecimento biomédico e em saúde contemporâneo.

Palavras-chave: Estudos Sociais em Ciência e Tecnologia, Sociologia do conhecimento científico, Pesquisa biomédica e em saúde, Biotecnologias emergentes, Ciências da vida.

\section{The dynamics of the biomedical and health knowledge: a sociological interpretation}

\section{Abstract}

The biomedical and health knowledge production has grown as a research object of Social Sciences. Scientific and technological changes, as well as the emergence of new social arrangements in the way research is conducted and agendas drawn up, have

* Universidade Estadual de Campinas, Campinas, SP, Brasil.

**Universidade de São Paulo, São Paulo, SP, Brasil. 
produced this interest. The aim of this essay is to present some central characteristics of this subject as an object of sociological research, for which we highlight three axes of analysis intertwined with each other, related to the transformations in the medical and health area, the pattern of financing research and its technological platform. Thereby, the text provides some tools to advance the research from the perspectives of social studies of science and of sociology on the production of biomedical knowledge and in contemporary health.

Keywords: Science and Technology Studies, Sociology of scientific knowledge, Biomedical and health research, Emerging biotechnologies, Life sciences.

\section{La dinámica del conocimiento biomédico y en salud: una interpretación sociológica}

\section{Resumen}

La producción de conocimiento biomédico y en salud ha crecido como objeto de investigación de las Ciencias Sociales. Los cambios científicos y tecnológicos, así como la emergencia de nuevos arreglos sociales en la manera de hacer investigación y en la elaboración de las agendas, produjeron ese interés. El objetivo de este ensayo es presentar algunas características centrales de ese tema como objeto de investigación sociológica, para lo cual destacamos tres ejes de análisis imbricados entre sí, relativos a las transformaciones en el área médica y de la salud, en el patrón de financiamiento a la investigación y a su plataforma tecnológica. Con eso, el texto proporciona algunas herramientas para avanzar en la investigación desde el punto de vista de los estudios sociales de la ciencia y de la sociología de la producción del conocimiento biomédico y en salud contemporáneo.

Palabras clave: Estudios Sociales de Ciencia y Tecnología, Sociología del conocimiento científico, Investigación biomédica y en salud, Biotecnologías emergentes, Ciencias de la vida. 


\section{Introdução}

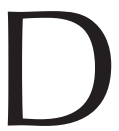

esde a primeira metade do século $X X$, a percepção sobre saúde e doença nas sociedades ocidentais modificou-se drasticamente. Por um lado, avanços técnicos e científicos promoveram a cura de inúmeras doenças e o aumento da expectativa de vida. Novos tratamentos, medicamentos e especialidades profissionais aprofundaram o alcance das ciências médicas de forma inédita, ampliando seu domínio temático e sua centralidade para a vida em sociedade (Conrad, 2007). Por outro lado, paradoxalmente, esses mesmos avanços complexificaram a percepção sobre o tema, multiplicando as controvérsias e incertezas: no decorrer do século passado, as mudanças no perfil epidemiológico contribuíram para a emergência de novas doenças e, com elas, novas percepções sobre os riscos ambientais e comportamentais; novos métodos de diagnóstico e intervenção se estabeleceram mas, ao mesmo tempo, as desigualdades no acesso à saúde se mantiveram ou se intensificaram (Albrecht et al., 2000). Em grande medida, como decorrência do aumento de tais incertezas em torno da eficácia das novas tecnologias em saúde, vis-à-vis seus impactos da reconfiguração das relações entre saúde/doença e sociedade, a área tornou-se um tema de pesquisa relevante para as Ciências Sociais e, desde então, mobiliza cada vez mais analistas e acadêmicos em diversas partes do mundo. Parte importante desses pesquisadores está vinculada ao campo dos chamados Estudos Sociais em Ciência e da Tecnologia (ESCT) ${ }^{1}$ - uma área do conhecimento interdisciplinar, voltada para o estudo da construção social do conhecimento e das novas tecnologias. Este é um campo dotado

${ }^{1} \mathrm{O}$ campo dos ESCT trabalha com um instrumental teórico derivado da Sociologia da Ciência, área que possibilitou a criação desse campo interdisciplinar. Ainda que os ESCT tenham se constituído como um campo autônomo, seus referenciais fazem parte do pensamento social e, em grande medida, da Sociologia da Ciência, campo que começou com Robert Merton na década de 1940 nos EUA. Para detalhes sobre o campo dos ESCT, ver Hess (2012), entre outros. 
de grande diversidade temática, com uma rica agenda de pesquisa que, sem dúvida, deve ser estimulada no Brasil ${ }^{2}$ (Spiess; Costa, 2014).

Este ensaio propõe uma revisão de literatura dos ESCT direcionada para uma análise abrangente dos principais elementos que caracterizam a dinâmica de produção do conhecimento biomédico e em saúde no mundo contemporâneo. Com o objetivo de conferir maior clareza na exposição dos argumentos centrais, o texto está dividido em quatro partes, seguidas por suas considerações finais.

A primeira parte apresenta o tema da pesquisa biomédica e em saúde pela ótica da Sociologia e dos ESCT. Na segunda, discute-se acerca do fortalecimento da agenda de pesquisa biomédica e em saúde no pósguerra, principalmente nos EUA e na Europa, que teve como resultado uma mudança no padrão de financiamento de C\&T nessa área. Na terceira parte, abordamos o desenvolvimento de sua plataforma tecnológica, sobretudo a partir dos anos setenta - num fenômeno que remete às transformações ocorridas nas formas de fazer pesquisa em saúde. Por fim, o artigo aborda um tema importante para a compreensão da dinâmica do conhecimento biomédico no fim do século XX e início do XXI, referente ao deslocamento da infraestrutura material e intelectual de pesquisa para os países em desenvolvimento. Com isso, o trabalho fornece algumas ferramentas dos ESCT para se avançar na pesquisa sociológica sobre a dinâmica de produção do conhecimento biomédico e em saúde no Brasil.

\section{A pesquisa biomédica e em saúde pela ótica da Sociologia e dos ESCT}

Em 2014, Spiess e Costa apresentaram um texto para uma coletânea sobre o pensamento dos ESCT na América Latina. Este paper teve o cuidado de resgatar a preocupação da Sociologia nos processos de construção do

${ }^{2}$ De acordo com Nunes (2014), as origens das análises sociais em saúde no Brasil "se firmaram a partir de datas muito recentes (segunda metade dos anos sessenta do século $X X$ ). Esses trabalhos apresentam ensaios, pesquisas, propostas para o ensino e projetos de intervenção, notadamente, por meio das atividades em educação sanitária. São ensaios sobre a medicina, a saúde, os remédios, os hospitais, as chamadas "doenças tropicais" com incursões em várias disciplinas, como a sociologia, a antropologia, a educação, a história, a geografia e o folclore" (Nunes, 2014, p. 1041-52). 
conhecimento médico. Entre os clássicos, denota-se a contribuição de Talcott Parsons (1951) que, de forma a sustentar seu argumento - funcionalista -, apresenta uma descrição de expectativas comportamentais, individuais e coletivas sobre as doenças nas sociedades ocidentais. Seus argumentos apontavam uma noção de desvio - doença -, que tornaria possível a isenção do indivíduo de suas tarefas - trabalho. A figura do médico tinha um papel central nos diagnósticos e acompanhamento da doença.

O comportamento doente (sick role, no original) dizia respeito ao desvio sancionado do indivíduo adoentado, bem como os regimes e direcionamentos que levam ao processo de cura. Para o autor, a condição de doença tornaria o indivíduo isento de suas atividades cotidianas, como o trabalho, ao mesmo tempo em que o obrigaria a agir de acordo com os processos de cura estabelecidos garantindo seu retorno ao estado normal (Parsons, 1951). Para isso, a figura do profissional médico assume um papel central, pois ele é socialmente autorizado a emitir os diagnósticos e conduzir os processos terapêuticos. Em uma direção semelhante, as instituições médicas e os papéis sociais relacionados com saúde e doença foram também abordados por Erving Goffman, autor com frequência vinculado à sociologia da medicina por sua obra a respeito das instituições totais como, por exemplo, os hospitais psiquiátricos (em Asylums: essays on the social situation of mental patients and other inmates, de 1961) e por sua reflexão sobre o conceito de estigma (em Stigma: notes on the management of spoiled identity, de 1963) (Spiess; Costa, 2014).

As formas com que os atores sociais e coletivos interferem na produção, circulação e no conteúdo do conhecimento (e, também, como estes interferem na organização dos cientistas e suas instituições sociais) se constituem como o principal objeto de análise dos ESCT. Desde a década de quarenta, quando emergiram como campo aplicado da pesquisa social, a premissa fundamental dos ESCT tem sido investigar a atividade científica enquanto uma construção social.

Os ESCT, quando iniciaram sua trajetória como um novo campo, herdeiro da Sociologia do Conhecimento, dividiram-se por mais de três décadas entre duas visões de mundo: uma perspectiva internalista e outra externalista. Na internalista, inaugurada por Merton, entendia-se que a 
produção de conhecimento científico é vista como um empreendimento dotado de sentido: assimila e reproduz valores e interesses compartilhados pelos cientistas em seus ambientes de interação, e os difunde para outros atores sociais, numa dinâmica que faz de suas instituições atores centrais da produção e circulação do empreendimento científico (Merton, 1973). Já a abordagem externalista considera a construção do conhecimento como um empreendimento coletivo e pautado numa intensa atividade em rede, interacionista e resultado de um processo de coprodução ${ }^{3}$.

Para Carvalho e colaboradores (2015), ainda que possamos apontar a tradição sociológica de Parsons na década de quarenta, o tema medicina e saúde ressurge como tópico importante da pesquisa social no começo da década de setenta, a partir da crítica à "ideia" de medicalização4. Concomitante à discussão sobre medicalização, a antropologia da medicina e a sociologia da saúde norte-americanas trouxeram, na década de oitenta, uma discussão mais elaborada sobre medicalização, passando a denominá-la biomedicalização, a partir dos trabalhos seminais de Adele Clarke. Tratavase de repensar o fenômeno de medicalização, da orientação generalizada e "estandardizada" sobre doença, medicamentos, vacinas, testes clínicos a partir do crescimento da pesquisa em biomedicina e de uma maior regulação estatal, por mecanismos ético-legais e novos arranjos organizacionais e

${ }^{3}$ De acordo com Gayard (2016, p. 62, citando Jasanoff, 2004), "coprodução implica reconhecer que as formas com as quais as sociedades aprendem, conhecem e representam a realidade - seja ela natural, material ou social - são indissociáveis das formas pelas quais escolhem viver na mesma. O conhecimento predominante nas sociedades, ao mesmo tempo em que conforma, também é conformado por elementos sociais, tais como práticas, identidades, normas, convenções, discursos e instituições. Da mesma forma que a sociedade não funciona sem o conhecimento, este não pode existir sem o suporte social apropriado." ${ }^{4}$ Carvalho e colaboradores (2015, p. 1252) apontam, com base em Rose (2007), que "o conceito de medicalização se consagrou a partir de estudos de investigadores da década de setenta, que tinham como referências iniciais as correntes marxistas e liberais humanistas. Em geral, a medicalização denota algo suspeito derivado da criação ou incorporação de um problema 'não médico' ao aparato da Medicina (Rose, 2007a). Na raiz desse fenômeno, o autor caracteriza a Medicina como uma instituição de controle social, dimensionando-a com ordem de grandeza tal como a religião e a lei. Em nome da produção de saúde, a Medicina tornava-se um repositório de verdade, um campo no qual juízos eram sentenciados por especialistas que portavam uma objetividade e uma moral supostamente neutras. Nesse contexto, o enfrentamento das doenças assumia ares de uma batalha moral, instigada por uma retórica que imputava responsabilidade e culpa ao indivíduo pelo seu próprio adoecimento". 
clínicos, como o da Medicina Baseada em Evidências e a Atenção Gerenciada à Saúde (Carvalho et al., 2015; Rose, 2007; Clarke et al., 2003).

O interesse antropológico e sociológico não se dirigiu apenas ao fenômeno do crescimento da pesquisa biomédica que, de fato, foi um movimento importante, mas claramente se voltou para o estudo das novas relações e transformações emergentes desse novo campo. Este, denominado "pesquisa biomédica e em saúde", é o conjunto ampliado de conhecimentos teóricos e metodológicos das ciências biológicas em sua interface com as ciências médicas e da saúde, que busca formular perguntas de pesquisa e sugerir explicações de caráter interdisciplinar, em que se viabilize uma intensa circulação de ideias, conceitos, ferramentas de pesquisa e, também, a idealização de "modos de fazer ciência" colaborativos e em redes. A pesquisa biomédica e em saúde é um campo de pesquisa voltado para compreender o funcionamento e a organização da vida humana desde as suas manifestações biológicas no nível genético/molecular até no plano das interações entre os indivíduos e suas práticas coletivas de saúde, tornando as fronteiras disciplinares cada vez mais fluidas e, portanto, possibilitando a formação de novas trajetórias acadêmicas (Camargo Jr., 2005).

Atualmente, a pesquisa biomédica é responsável pelo maior volume de publicações científicas nos países industrializados, sendo considerada uma área que recebe grandes investimentos por parte do setor público (via iniciativas governamentais ou, no caso de alguns países, via Política Científica e Tecnológica - PCT) e do setor privado (na forma de investimentos em Pesquisa e Desenvolvimento (P\&D) por parte da indústria da saúde, seja pelo fomento intramuros de universidades e centros de pesquisa privados, ou agências filantrópicas sem fins lucrativos (Owens, 2014; Silva; Novaes, 2018; Malnic, 2007).

O relatório OECD Science, technology and innovation outlook 2016 apresentou um panorama importante sobre a aparente especialização de alguns países em dirigir os dispêndios públicos para temas relacionados à saúde. Por exemplo, os Estados Unidos têm uma clara orientação política para P\&D em saúde, que absorveu 24\% dos investimentos públicos com P\&D em 2016. Reino Unido e Canadá, outros grandes polos globais de pesquisa em saúde, dedicam em média um quinto de seus orçamentos de 
P\&D à investigação de temas nesta área, tendo investido respectivamente $22 \%$ e $17 \%$ no mesmo ano (OECD, 2016).

De acordo com Moses e colaboradores (2015), estima-se que em 2011 tenham sido investidos em torno de 265 bilhões de dólares em pesquisa biomédica e em saúde no mundo, e que $66 \%$ desse montante provenha de entidades do setor privado. Considerando-se os investimentos nessa área por parte de países como a China e o grupo Índia, Cingapura e Coreia do Sul, entre 2004 e 2011 houve um crescimento anual dos investimentos na ordem de $16,9 \%$ e 20,8\%, respectivamente, consolidando o forte dinamismo da região na pesquisa biomédica e em saúde na primeira década do século XXI (Moses et al., 2015). As informações referentes a esse investimento em outros países e regiões do mundo estão disponíveis na Figura 1.

Figura 1: Dispêndio global (público e privado) com pesquisa biomédica e em Saúde, países/regiões selecionadas, 2011.

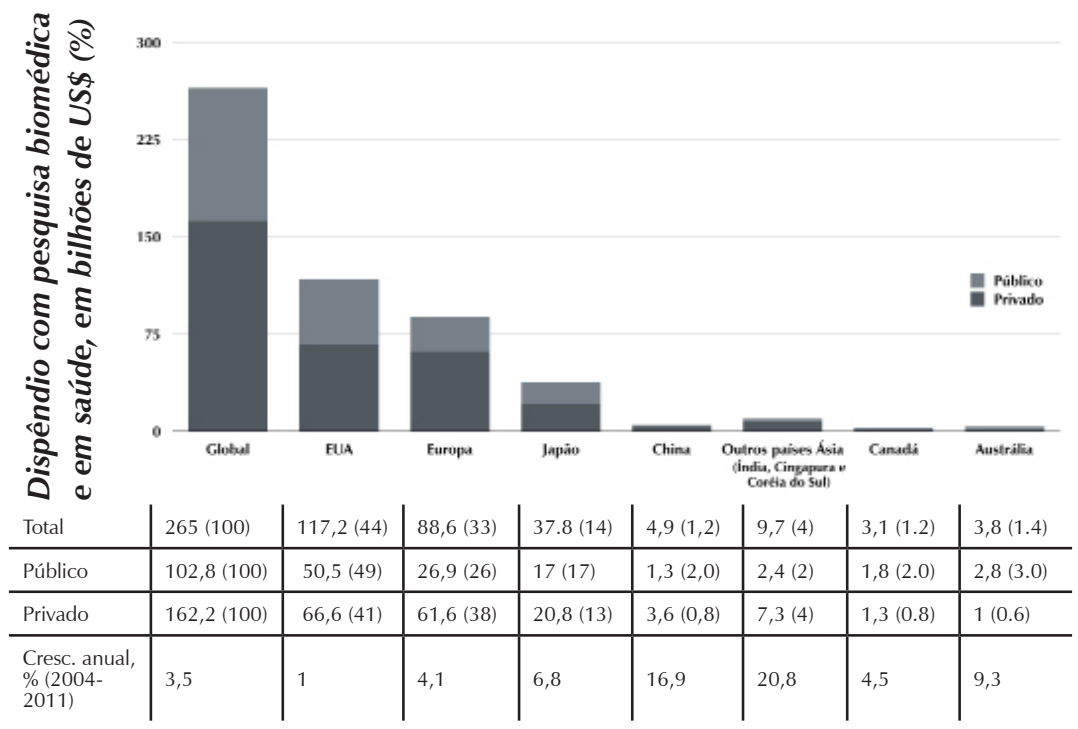

Fonte: elaboração própria, com extração dos dados na íntegra de Moses et al. (2015). 
A pesquisa biomédica e em saúde possui grande relevância no cenário científico e tecnológico internacional, o que, em grande medida, justifica o interesse de sociólogos da ciência e da tecnologia para esse tema como um objeto de pesquisa por excelência. Como esse artigo irá demonstrar nos próximos tópicos, na virada do século XXI os ESCT não se restringiram apenas ao estudo das ciências da vida humana nos países de industrialização madura, mas também focalizaram seus projetos de pesquisa em compreender as novas manifestações desse campo nos países em desenvolvimento (Gibbon et al., 2018).

Nesse contexto, as ciências sociais e os ESCT passaram a investigar o papel dos atores não governamentais e dos movimentos sociais na promoção política de novas agendas para a saúde; nas implicações (bio)éticas do uso e circulação de novas biotecnologias; na reorganização das instituições médicas e em suas políticas de regulação para novos medicamentos; na organização da comunidade científica e sua inserção em novos temas de interesse público (como a Saúde Pública); nas formas encontradas pelos países em desenvolvimento (como Brasil, Índia, China etc.) para incorporar uma nova plataforma produtiva em áreas complexas das ciências da vida, como a medicina regenerativa, terapias reprodutivas, terapias personalizadas, medicamentos biológicos e novas terapias-alvo, entre outros temas (Nelson, 2016; Fagot-Largeaut, 2004).

É crucial, portanto, uma análise mais específica sobre as características atribuídas a esse tema de pesquisa por parte dos ESCT. Muito embora seja difícil propor uma tipologia sobre a evolução desse tema dentro das ciências sociais desde a sua origem no século XX, o objetivo aqui é propor um exercício intelectual de entendimento da literatura, que sirva mais para localizar o leitor diante de alguns eixos de discussão de grande relevância para o estudo social da pesquisa biomédica e em saúde ao longo das últimas décadas, mas que não posicione esse debate como limitado às fronteiras disciplinares das ciências sociais.

Esse é, sem dúvida, um exercício arbitrário, mas que cumpre uma função importante nesse trabalho e no presente dossiê, que é fornecer uma breve apresentação de uma literatura e com referenciais ainda não totalmente difundidos nas ciências sociais no Brasil. Para isso, sugerimos 
três eixos de discussão: o financiamento à pesquisa, transformações na plataforma tecnológica e a globalização do conhecimento em biomedicina.

\section{Mudança no padrão de financiamento à pesquisa}

Em 14 de novembro de 2014, uma matéria especial publicada no The New York Times Magazine intitulada Why are so few blockbuster drugs invented today? (Hurley, 2014) apresentou um interessante panorama sobre a atividade de pesquisa biomédica e em saúde nas últimas décadas. A matéria é uma crítica assertiva ao oneroso (e demorado) sistema para se lançar novas tecnologias em saúde. O texto argumenta que, muito embora tenham crescido drasticamente os investimentos em P\&D dos governos e da indústria farmacêutica com novos medicamentos desde os anos cinquenta, o lançamento de novas tecnologias no mercado tem diminuído rapidamente.

$\mathrm{O}$ artigo cita dados dos pesquisadores Scannell e Warrington, que trabalharam por quarenta anos coordenando projetos de novas moléculas para empresas farmacêuticas. Eles publicaram um relatório inconveniente em 2012, em que mostram que para cada bilhão de dólares gasto com P\&D desde 1950, a média de novos medicamentos aprovados por ano caiu pela metade a cada nove anos. O relatório foi considerado alarmante e gerou ampla discussão entre a indústria e a comunidade científica nos Estados Unidos (Hurley, 2014).

A matéria destacou ainda que essa conjuntura de baixa performance do desenvolvimento tecnológico em saúde é diametralmente oposta ao que foi prometido como o futuro da pesquisa biomédica no fim dos anos noventa. Esta conjuntura está relacionada ao período marcado por grande expectativa internacional em torno do lançamento do chamado Projeto Genoma Humano, em 1999. Este ambicioso programa de pesquisa, coordenado pelos Institutos Nacionais de Saúde dos EUA (National Institutes of Health - NIH) tinha como objetivo mapear uma grande parte do DNA de seres humanos (genoma): uma iniciativa pioneira na história da ciência contemporânea.

Para mostrar o impacto desse evento no imaginário social da época, a publicação do jornal norte-americano sustentou que "o clamor pela genômica nos anos noventa soava similar às previsões feitas na década de 
cinquenta para carros voadores e dispositivos anti-gravidade" ${ }^{\prime 5}$. O projeto foi organizado no formato de consórcio internacional de sequenciamento de segmentos expressos de DNA, que mobilizou pesquisadores de institutos de pesquisa e empresas de biotecnologia de 17 países por mais uma década (Nature, 2001).

No início do século XXI, a literatura produzida pelos ESCT destacou que os movimentos científicos levados a cabo pela pesquisa biomédica e em saúde marcaram a própria história da ciência no século XX. De acordo com Keating e Cambrósio (2006), sobretudo desde meados dos anos cinquenta, a construção desse campo é resultado de um contínuo processo de colaboração entre as associações de especialistas em universidades e outros espaços acadêmicos, os governos e suas agências de regulação e controle sanitário e as organizações provedoras de serviços de saúde, como hospitais e centros de saúde. Em conjunto, essas instituições foram capazes de posicionar a pesquisa biomédica em outro patamar de legitimidade social diante das incertezas políticas experimentadas no período. Essa relação se desenvolveu significativamente ao longo do século passado e foi capaz de criar uma plataforma de políticas de ciência e tecnologia favoráveis à continuidade dessa atividade profissional, com a condição de que lograsse fornecer respostas práticas para atender aos anseios da sociedade em geral (Keating; Cambrósio, 2006).

Se compreendida em perspectiva histórica, a origem desse processo de formação de alianças é controversa ${ }^{6}$. Parte relevante dos historiadores da ciência considera que o campo possui um marco central em meados do século XX - remetendo ao contexto de reformas nos sistemas de ciência e

\footnotetext{
${ }^{5} \mathrm{Na}$ versão original "The claims made for genomics in the 1990s sound a bit like predictions made in the 1950s for flying cars and anti-gravity devices" (The New York Times, 2014 [online]).

${ }^{6}$ Por uma questão de espaço e escopo do artigo, não abordaremos esse debate com a dedicação merecida. No entanto, é importante considerar que cada área das ciências sociais dá destaque para movimentos científicos ocorridos em diferentes períodos do século XX, seja para o primeiro quartel do século XX (momento de expansão da pesquisa biológica e de consolidação das instituições científicas), seja ao longo da primeira metade do século XX ou mesmo no período do pós-guerra. Uma linha importante de historiadores da ciência admite que foi nesta última que se presenciou uma reconfiguração institucional e no conteúdo da pesquisa biomédica, para a qual daremos destaque.
} 
tecnologia experimentados pela Europa e EUA no imediato pós-guerra. Para Chadarevian e Kamminga (1998), esse período é considerado paradigmático para o desenvolvimento da pesquisa biomédica e em saúde nos países industrializados, tendo ganhado evidência, sobretudo, devido ao impacto político dessa agenda de pesquisa com a emergência da chamada biologia molecular ${ }^{7}$. As autoras sugerem que essa nova área cumpriu bem o papel de atender aos anseios dos governos nacionais naquele período, cujo objetivo era vincular a imagem da ciência e da tecnologia (portanto, dos cientistas) como aliadas ao projeto de desenvolvimento econômico e social em vias de implementação ${ }^{8}$ (Chadarevian; Kamminga, 1998).

Para os ESCT, alguns elementos permitem verificar o impacto político desse pacto. Um deles, bastante destacado pelo campo Ciência, Tecnologia e Sociedade (CTS) em geral, aborda a promoção de iniciativas robustas de financiamento público à pesquisa científica nos anos cinquenta e sessenta, com a expansão dos programas de governo para ciência nas universidades e institutos de pesquisa - conjuntura que ficou conhecida como a Era da Big Science. Segundo Solla Price (1963), como reflexo dessa reforma nas políticas de C\&T, a mobilização de recursos para essa finalidade mais que dobrou no período de 1950 a 1962. A ciência se difundiu como ativo estratégico fundamental dos governos para atender às novas demandas de reconversão das economias nacionais (Solla Price, 1963).

Portanto, há certo grau de consensualidade nessa literatura em que o encerramento da segunda guerra mundial marcou uma entrada expressiva da ciência e da tecnologia na agenda política dos governos, fortalecendo as narrativas de progresso que buscavam legitimar os regimes democráticos

\footnotetext{
${ }^{7}$ De acordo com Fox-Keller (2002), a biologia molecular é o campo que estuda a organização, a estrutura e o funcionamento do DNA de organismos vivos, assim como os processos de ativação da informação genética que residem em tal estrutura e regulam o desenvolvimento e a reprodução celular. Para uma breve discussão sobre a biologia molecular, ver Silva e Costa (2018).

${ }^{8}$ Para ver detalhes sobre a construção das alianças políticas na emergência da biologia molecular no pós-guerra, ver Chadarevian e Kamminga (1998) e Strasser (2002).
} 
como sistemas mais avançados de organização da sociedade ${ }^{9}$. Nesse contexto, a pesquisa biomédica e em saúde teve amplo destaque.

Esse movimento avançou ao longo das décadas seguintes, provocando uma mudança expressiva no padrão de financiamento para essa área. A partir dos anos setenta, a pesquisa biomédica e em saúde adquiriu enorme importância na política oficial de vários países. Nos EUA, por exemplo, na esfera das políticas federais, parte robusta dos financiamentos para essa área foi executado pelos $\mathrm{NIH}$ - instituições que mantêm seu protagonismo na promoção de C\&T em saúde naquele país até os dias atuais (Moses, 2015).

Osthus e Benos (2006) sustentam que os EUA avançaram na promoção de grandes programas de investimentos federais para temas aplicados à saúde humana - área chamada de Ciências da Vida (Life Sciences). Segundo esses autores, duas narrativas passaram a dominar a pesquisa biomédica e em saúde a partir dos anos setenta: a primeira, mais objetiva, referente ao crescimento acelerado dos financiamentos, em escala e em complexidade; a segunda, relativa à emergência de novas questões éticas suscitadas pela inclusão de seres humanos como objetos de pesquisa. É preciso relembrar que a pesquisa com seres humanos é um fenômeno relativamente recente, que certamente interferiu no conteúdo e na dinâmica do conhecimento em saúde ao longo das últimas décadas (Osthus; Benos, 2006).

O novo padrão de financiamento alcançado por essa área de pesquisa, portanto, é um fenômeno que tem sido reportado com relativa continuidade dentro dos ESCT. Ele evidencia um dado importante para os pesquisadores em ciências sociais, que sugere uma tendência (band wagoning) da comunidade científica em promover suas agendas de pesquisa e inseri-las no circuito

\footnotetext{
${ }^{9}$ Nos Estados Unidos, a ciência adquiriu enorme importância, marcando uma conjuntura histórica que ficou conhecida como a Era da Big Science: momento em que o governo federal dos EUA passou a definir um sistema coordenado de políticas para a ciência e, também, para a tecnologia $(\mathrm{C} \& \mathrm{~T})$. A Era da Big Science está relacionada à emergência de um novo padrão de intervenção estatal para definir e fortalecer uma política científica e tecnológica nos EUA do pós-guerra. Essa narrativa foi principalmente inspirada pelo relatório Science: the endless frontier organizado em 1945 por Vannevar Bush, diretor da unidade de aconselhamento de políticas para pesquisa e desenvolvimento da presidência dos EUA (Office of Scientific Research and Development). No documento, Bush recomendou algumas ações no campo da C\&T para o então presidente Franklin Roosevelt: o texto do documento estava ancorado na ideia de que promover a ciência era sinônimo de promoção do desenvolvimento econômico e social (National Science Foundation, 1945).
} 
mais amplo das políticas democráticas. Nesse processo, o convencimento dos policy makers sobre a relevância econômica e social das agendas de pesquisa em saúde (com ampla vinculação com o discurso da inovação e da bioeconomia) construíram um sistema virtuoso para a evolução dessa área, com impactos reais para a ampliação de sua plataforma material e seu alcance geográfico (Mittra, 2016).

\section{Transformações na plataforma tecnológica}

Uma maneira tradicional dos ESCT de análise do desenvolvimento científico na pesquisa biomédica e em saúde é pela via da compreensão do uso de novas tecnologias na produção de conhecimento. No período entre o pós-guerra e a primeira década do século XXI é possível observar uma extraordinária expansão da atividade científica e tecnológica em saúde, com um emergente parque biotecnológico que resultou em uma nova forma de se produzir conhecimento. Para Bornmann e Mutz (2015), a pesquisa biomédica e em saúde, junto com as ciências naturais (principalmente a física e a química), protagonizou um movimento de expansão da produção científica entre o pós-guerra e o ano de 2012, num período de crescimento médio anual de 8-9\% (comparado à taxa de 2-3\% no período entre guerras). Segundo o estudo, o período iniciado no pós-guerra registrou um número de publicações três vezes maior que o período anterior (Bornmann; Mutz, 2015).

Em linhas gerais, é possível afirmar que a literatura dos ESCT dedica ampla atenção para o estudo de dois movimentos científicos e tecnológicos particulares ao século XX, no que se refere à mudança de paradigmas na maneira como os cientistas organizam e produzem o conhecimento biomédico e em saúde. O primeiro deles (que representou também uma mudança de paradigma epistemológico) foi a idealização do modelo em hélice dupla da estrutura do DNA nos anos cinquenta. Segundo Evelyn Fox Keller, em seu livro intitulado The century of the gene (Fox-Keller, 2002), a biologia molecular representou a introdução de uma nova epistemologia para a pesquisa biomédica e em saúde. Com a proposição da estrutura básica do DNA (também chamada de "dogma central da biologia molecular") difundiu-se uma nova forma de compreender a vida biológica, que propôs 
uma lógica distinta de compreensão da reprodução e crescimento celular. Naquele período, o desenvolvimento científico e tecnológico da pesquisa biomédica e em saúde foi marcado por entendimento mais específico dos sistemas biológicos e de seu funcionamento, que resultou na publicação de centenas de trabalhos acadêmicos sobre modelos de imagens tridimensionais de estruturas moleculares. As tecnologias emergentes da física nuclear (como, por exemplo, a cristalografia de Raio-X) foram aos poucos incorporadas ao campo, reorganizando o parque tecnológico e tornando-se, portanto, uma das características centrais dessa área emergente (Fox-Keller, 2002).

Como um reflexo dessa transformação, a conjuntura do pós-guerra foi marcada pela formação de novas redes internacionais de pesquisa, configurando um arcabouço institucional distinto para essa nova área. Esse novo desenho gerou reflexos na definição das políticas de C\&T, principalmente nos países de industrialização consolidada, assim como reorganizou as prioridades dos governos sobre "quais áreas da ciência seriam privilegiadas para se investir" e "qual será a aplicação desse novo regime técnico e científico da pesquisa biológica". A trajetória escolhida por aqueles países foi direcionar essa plataforma tecnocientífica para a pesquisa biomédica - principalmente focada na produção e comercialização de novos medicamentos. O objetivo era substituir (em algumas décadas) a antiga infraestrutura de pesquisa e produção de fármacos sintéticos - instalada pelo paradigma anterior da química fina, em uso desde a primeira metade do século XX. Sua configuração deveria favorecer um duplo empreendimento: desenvolver o parque científico nacional de forma integrada a uma reforma tecnológica do sistema produtivo em saúde (Mowery, 1998).

Ainda no que diz respeito ao papel da mudança tecnológica na produção de conhecimento biomédico na segunda metade do século $X X$, os anos setenta brindaram outra transformação nesse campo. Nessa direção, os ESCT destacam o papel desempenhado pela emergência das chamadas tecnologias de informação e comunicação no desenvolvimento de novas agendas de pesquisa biomédica no último quartil do século XX.

Segundo o historiador Bruno Strasser (2010), ao longo dos anos setenta e oitenta, a maneira como o pesquisador passou a "fazer ciência" foi alterada principalmente devido ao impacto das novas técnicas de computação e 
análise de dados introduzidas no cotidiano da atividade de pesquisa. Em seu trabalho Collecting, comparing, and computing sequences: the making of Margaret O. Dayhoff's Atlas of protein sequence and structure, 1954-1965 (Dayhoff et al.1965), Strasser demonstra como a pesquisadora americana introduziu a técnica de sequenciamento de DNAs no seu laboratório da Universidade de Michigan, nos EUA, no início dos anos sessenta. O trabalho contribui para a discussão sobre o impacto das mudanças ocorridas na plataforma tecnológica com a introdução da interdisciplinaridade no interior dos laboratórios de pesquisa biomédica. Esse fenômeno interferiu sobremaneira na idealização das perguntas, hipóteses e metodologias de pesquisa. As mudanças na capacidade de armazenar os dados criaram novas possibilidades para pesquisas mais ambiciosas (Strasser, 2010).

O último quartil do século XX foi um momento importante para o próprio questionamento sobre o conhecimento médico por parte das ciências sociais. Por volta dos anos setenta, este questionamento mesclou-se à ideia do construtivismo da realidade proposta por Berger e Luckmann (1967), em que o mundo social é constituído pela "reprodução de significado e conhecimento", de maneira que as relações sociais e a própria realidade são dependentes de processos de socialização e de "definições compartilhadas" sobre a natureza e a sociedade (Berger; Luckman, 1967).

Vale lembrar que, a seu próprio modo, os trabalhos de Michel Foucault se tornaram particularmente importantes para a problematização da medicina e da saúde naquele período - algo que implicou no desenvolvimento de uma importante linha de investigação sobre a saúde e seus significados políticos e sociais nas décadas seguintes. Na década de setenta, Foucault explorou diversos temas e conceitos que viriam a influenciar a reflexão das humanidades sobre saúde, doença e corpo nas sociedades modernas (Zorzanelli; Cruz, 2018).

Desde então, tais ideias foram fundamentais para popularizar a discussão sobre o papel das novas tecnologias médicas na reconfiguração daquelas categorias sobre saúde/doença e corpo, como é o caso da questão presente no livro de Linda Nicholson (1990) Feminism/Postmodernism - este que contém o conhecido capítulo A manifesto for cyborgs: science, technology and socialist feminism in the 1980s, de Donna Haraway. 
Nas últimas décadas do século XX, a geoeconomia da biotecnologia ${ }^{10}$ estava em rápida transformação, instalando-se em regiões e contextos culturais diversificados se comparados ao período pré-1980. Dentre outros fatores, esse processo ganhou dimensão devido à expressiva realocação territorial da infraestrutura de alta tecnologia que deixou de ser exclusividade dos países desenvolvidos, passando a se reorganizar num contexto regido pela lógica das teorias da globalização, particularmente dominantes nos espaços intelectuais da sociologia nos anos noventa (Nowotny et al., 2001).

Esses movimentos tiveram reflexos para a produção de conhecimento nos ESCT. Na virada do século XXI, impulsionados pela expectativa em torno dos resultados do Projeto Genoma e suas implicações na sociedade, cada vez mais pesquisadores voltaram a atenção para o estudo da globalização e seus impactos na pesquisa biomédica e em saúde (Fox-Keller, 2002). Este tema ganhou relevância e teve reflexos em novos contextos regionais e locais, o que permitiu a emergência de novas questões (Leach; Scoones, 2015). Os ESCT passam então a "descortinar" novas experiências de organização da pesquisa biomédica para além de suas teorias e práticas nos países desenvolvidos, com resultados importantes para a discussão nas primeiras duas décadas do século XXI.

\section{A globalização do conhecimento biomédico}

A emergência de uma vasta literatura sobre os processos de globalização teve um enorme impacto na forma com que os cientistas sociais passaram a interpretar o desenvolvimento científico e tecnológico no campo da pesquisa biomédica. Muito embora os sociólogos já tivessem dado a devida atenção para o papel da circulação do conhecimento e das ideias na evolução da

\footnotetext{
${ }^{10} \mathrm{~A}$ ideia de "geoeconomia da biotecnologia" remete aos aspectos geográficos e territoriais da biotecnologia como atividade econômica intensiva em conhecimento e em tecnologia. Nesse sentido, esse tem sido um recorte comum para os ESCT e, mais especificamente, aos estudos dirigidos à dinâmica da inovação e desenvolvimento econômico contemporâneo. Por abordar elementos materiais caros à evolução do conhecimento em determinadas regiões do mundo, essa dinâmica guarda uma relação intrínseca com o tema da pesquisa biomédica e em saúde, já que influenciou a própria configuração das relações sociotécnicas dessa área ao longo das últimas décadas. Em Mittra (2016), o leitor pode encontrar um interessante material de análise sociológica construída sobre esse recorte.
} 
ciência, o fim do século XX ampliou esse debate de forma mais explícita nos ESCT. A discussão voltou-se para uma agenda crítica do processo de globalização, em que se destacam os temas da desconcentração geográfica da plataforma da biotecnologia de alta tecnologia, e um movimento de padronização global da política científica e tecnológica que se estende até a atualidade (Lowy; Gaudillière, 2008).

Lock e Nguyen (2010) propuseram uma leitura crítica sobre essa dinâmica na pesquisa biomédica e em saúde contemporânea. De acordo com os autores, nas últimas décadas a comunidade acadêmica internacional empreendeu um esforço massivo de padronização dos regimes locais de produção do conhecimento científico e, também, no que diz respeito à prática médica ocidental. Dedicados especificamente ao estudo da produção de conhecimento biomédico nos últimos trinta anos, seu argumento está fundado na ideia de que a globalização de biotecnologias médicas, criadas e aprimoradas nos países ricos, tem servido como instrumento de reprodução de relações coloniais para o exercício da prática científica em outras regiões do mundo. As incoerências da importação desse modelo por parte dos países pobres e em desenvolvimento ficaram explícitas nos custos de aquisição, gestão e manutenção de equipamentos, na dependência por reagentes, linhagens e culturas de células, aparelhos de sequenciamento de informações genéticas, novos insumos de laboratório etc. Ainda, segundo os autores, no fim do século XX, a construção de novas políticas nacionais de ciência e tecnologia mundo afora priorizou um tipo de produção de conhecimento bastante específico e particular dos países de alta renda (Lock; Nguyen, 2010).

Assim, como apontado por Lock, o aumento da expansão transnacional da pesquisa e das tecnologias genômicas é muitas vezes ligado de maneira pró-ética e prática a esforços "humanitários" para ampliar a inclusão, o acesso e a participação (dentro) e muito além do "norte global". No entanto, esse mesmo processo pode, ao mesmo tempo, revelar as desigualdades que têm e continuam a moldar esses desenvolvimentos. Isso, portanto, constitui outra tensão central. Vemos como as histórias coloniais e pós-coloniais da pesquisa científica e das assimetrias de poder continuam a ter um lugar central na ciência e na medicina genômica. Esse processo tem sido ampliado, 
apoiado no discurso de melhorar a saúde dos pobres a partir do uso de alta tecnologia - um objetivo louvável, ainda que raramente as populações de baixa renda tenham acesso a tais tecnologias (Gibbon et al., 2018).

Lock e Nguyen apontam, ainda, que a discussão sobre o modelo biomédico não pode ser separada de uma consideração de interesses e objetivos globais como os da Organização Mundial da Saúde (OMS), da Organização das Nações Unidas para a Educação, a Ciência e a Cultura (UNESCO), de governos de países ricos e pobres, grupos de interesses, multinacionais e indústrias, associações médicas e ONGs. Todos esses ao menos uma vez facilitaram ou impediram a distribuição dessas tecnologias (Lock; Nguyen, 2010, p. 432-3).

Por sua vez, Biehl e Mohan-Thomas (2009) assumem que a biomedicina não apenas se globalizou, mas adotou um modelo "global" para todos os países, deixando de lado realidades e demandas próprias aos contextos culturais locais. Ainda, à medida que os serviços de atenção à saúde são cada vez mais terceirizados para empreendedores e comunidades locais, e à medida que medicamentos poderosos circulam sem a visita a um médico, os autores concluem que as relações humanas com a tecnologia médica constituem-se, cada vez mais, fora do encontro clínico.

A revisão dessa literatura crítica da biotecnologia sugere que a globalização na biomedicina aprofundou a hierarquia entre o Norte e o Sul. As empresas farmacêuticas e de novas tecnologias para a área médica (as mesmas que, também, concentram os recursos para o fomento da pesquisa genômica aplicada e clínica) têm colaborado com um aprofundamento dos padrões de medição dos corpos - ainda que uma parte da pesquisa venha sendo desenvolvida no Sul (Bowker; Star, 1999) ${ }^{11}$. Além disso, na esteira desse movimento, que Lock (1995) denominou local biologies, há uma referência importante das ciências sociais sobre a inseparabilidade e imbricação dos processos sociais e biológicos, que resultam em seres humanos biologicamente distintos, dependendo do contexto - socioeconômico, histórico, geográfico, cultural etc. Para os autores, o termo

${ }^{11}$ Outras leituras apontam que novas populações terapêuticas e formas de intimidação emergem em torno da noção de tecnologia e no nível doméstico, como é o caso da disseminação não regulada de drogas psiquiátricas no mundo todo (Luhrman, 2002; Ecks, 2005; Petryna et al., 2006; Biehl, 2008; Fischer, 2009; Biehl; Petryna 2011; Jenkins, 2011). 
local biologies significa que processos biológicos e sociais são inseparáveis e imbricados ao longo do tempo, resultando em um ser humano biologicamente distinto - distinção que pode ou não ser subjetivamente discernida por indivíduos. Quando essa subjetividade dos pacientes é reportada aos médicos, as manifestações da biologia local podem ser colocadas de lado, ou até descartadas. No entanto, esta também tem aparecido nos laboratórios, e hoje há uma atenção sistemática à diferença biológica nas pesquisas sobre genética molecular e populacional. Tais diferenças são, obviamente, publicadas em revistas médicas e frequentemente aparecem na mídia. O entrelaçamento de processos biológicos e sociais é, às vezes, proposital, como quando a eugenia é colocada em prática, ou tentativas são feitas na engenharia de saúde pública, mas, na maioria das vezes, é incidental, desprovida de qualquer objetivo teleológico, e é o resultado, por exemplo, de práticas agrícolas ou poluição industrial (Lock; Nguyen, 2010, p. 2784-90, tradução nossa).

Ainda no âmbito dessa discussão, uma outra questão que se apresenta é a proeminência de imaginários da genômica e da pós-genômica como fonte de inovação e valor. A emergência do termo "bioeconomia", desde o Human Genome Project (HGP), estimulou investimentos em dinheiro, talento e esperança em novas possibilidades tecnológicas - expressas pelas autoridades dos governos, das finanças e da biomedicina, bem como pelos grupos de aconselhamento ao paciente e muitos outros (Hajer, 2009). Estas mudanças transformaram a bioeconomia em um objeto apropriável por parte dos formuladores de políticas, investidores e outros interessados, como elemento de autopromoção em seus circuitos de interação com a academia, a indústria e a sociedade.

Os desafios de governar a inovação em genômica têm sido uma preocupação importante dos formuladores de políticas científicas e dos analistas sociais. Desde seus primeiros dias, a genômica tem sido um locus de coprodução e compartilhamento de novas formas de conhecimento e novos regimes de controle. Os autores colaboradores deste dossiê avançam nessa direção, com a proposta de trabalhos que exploram como a governança do conhecimento em genômica médica e outras biotecnologias tem se tornado um processo complexo e distributivo, envolvendo uma variedade de mecanismos regulatórios, tanto formais quanto informais, que são frequentemente contestados e reproduzidos (Hilgartner, 2017). 
Na dinâmica de organização desse sistema, estruturas regulatórias e conceitos formais são frequentemente desafiados por novos desenvolvimentos, e fronteiras jurisdicionais, formais e informais estão sendo reconfiguradas. Ao mesmo tempo, num nível quasi-institucional, o conceito de imaginários sociotécnicos ${ }^{12}$ ajuda a estabilizar alocações de autoridade fundamentadas na ontologia do modelo linear de inovação, modelo colocado em possível situação de mudança nas últimas duas décadas (Jasanoff; Kim, 2015).

Uma manifestação importante desse processo se deu no âmbito das políticas públicas. De acordo com Velho (2010), nas últimas décadas foram desenvolvidos vários modelos explicativos da relação entre ciência, tecnologia e sociedade e sobre a produção e uso do conhecimento. Em geral, todos esses modelos, apesar de trabalharem com categorias analíticas diferentes, enfatizam a relação não linear entre pesquisa e produção, concebem os processos de geração e uso de conhecimento como sendo de natureza muito mais complexa, envolvendo vários atores localizados e interagindo em contextos sociais particulares (Velho, 2010) ${ }^{\mathbf{1 3}}$.

\section{A estrutura do dossiê}

Como parte do presente dossiê "Sociologia do conhecimento biomédico", esse artigo busca introduzir e circunscrever os trabalhos consecutivos apresentados neste número da revista Sociologias (UFRGS). No que diz respeito aos trabalhos aqui publicados, trata-se de um excelente (e atual) material de pesquisa sociológica, que resgata críticas fundamentais sobre o processo de construção social do conhecimento biomédico contemporâneo - seja decorrente das práticas científicas, seja do aprendizado gerado na produção de políticas e inovações tecnológicas aplicadas à saúde humana. Apresentando distintas abordagens teóricas e

${ }^{12} \mathrm{O}$ conceito de "imaginários sociotécnicos" representa o conjunto de visões, valores e perspectivas que orientam os processos decisórios do Estado na perseguição de trajetórias científicas e tecnológicas. Esta perspectiva permite explicar as bases das variações nas políticas de ciência e tecnologia perseguidas pelos Estados (Jasanoff, 2004).

${ }^{13}$ Os principais modelos propostos pela literatura são: Modo 1 e Modo 2 (Gibbons et al., 1994); sistemas nacionais de inovação (Freeman, 1995); hélice tripla (Etzkowitz; Leydesdorff, 2000); construção social da tecnologia (Bijker, 1995); teoria Ator-rede (Latour; Woolgar 1979; Callon, 1987). 
metodológicas, os textos fortalecem o caráter interdisciplinar desse campo, que é uma característica necessária para que se dê conta da complexidade das transformações (e também das permanências) do conhecimento biomédico nas últimas décadas.

O artigo Embodied values: post-pharmaceutical health and the accumulation of surplus vitality in regenerative stem cell medicine, de autoria de Christian Haddad (Austrian Institute of International Affairs), é um exemplo interessante de como as novas tecnologias têm alterado as concepções de vida e saúde nas sociedades capitalistas contemporâneas. A argumentação sustentada é a de que a maior oferta de terapias (Haddad usa como estudo de caso aquelas baseadas em células-tronco) tem permitido a configuração do que o autor chama de "saúde pós-farmacêutica". Esse novo tipo de condição humana tem como fenômeno central a possibilidade de "acumulação" de "vitalidade excedente", que se reproduz num ambiente marcado pela dinâmica dos negócios da bioeconomia, em que se promove incessantemente, na cultura capitalista, a busca por novas tecnologias em saúde (mais modernas, mais controversas e também mais caras). Esse sistema de relações, construído como fenômeno particular ao século XXI, tem permitido a emergência de novas formas de subjetividade na relação com a saúde, o corpo, a ciência e a tecnologia.

Seguindo uma abordagem crítica sobre os fatores sociais que interferem na produção do conhecimento científico, agora aplicada especificamente à prática científica que ocorre nos laboratórios, o artigo Periferia pensada em termos de falta: uma análise do campo da genética humana e médica, de Mariana Toledo Ferreira (Instituto Federal de Educação, Ciência e Tecnologia de Goiás) fornece uma excelente discussão sobre as assimetrias presentes nas condições materiais e intelectuais nas ciências biomédicas no Brasil. O texto sustenta a ideia de que os cientistas, ao articularem discursivamente uma caracterização da pesquisa biomédica no contexto local brasileiro, descrevem essa prática como mediada em termos de falta, em que se dá ampla atenção para a escassez das condições materiais para se produzir ciência no país. O trabalho avança mostrando que essa narrativa se constrói como parte importante do imaginário do cientista nas áreas de genética humana e médica, que se localiza como pertencente a uma condição 
de periferia do sistema científico de excelência. Em grande medida, essa comparação decorre do contato dos pesquisadores com uma realidade do exterior, e a autora demonstra que isso pode ser entendido como um reflexo das relações de dependência cognitiva, nos moldes propostos pelas Teorias da Dependência latino-americanas na segunda metade do século XX. O trabalho representa, portanto, um diálogo importante e raramente encontrado na literatura dos ESCT, em que se utilizam "nossas teorias" para explicar um fenômeno local marcado por um constante reforço das relações centro-periferia na ciência, que é uma prática intrínseca à própria dinâmica do conhecimento científico.

Propondo uma discussão similar, mas focada no âmbito das iniciativas de governança da pesquisa biomédica e do desenvolvimento tecnológico em saúde na América Latina, o artigo Shaping stem cell therapies in Argentina. Regulation, risk management and innovation policies, de Gabriela Bortz (Universidad Nacional de Quilmes), Achim Rosemann (University of Exeter) e Frederico Vasen (Universidad de Buenos Aires), apresenta um estudo de caso que demarca com clareza os desafios presentes na construção de um sistema de regulação para terapias baseadas em células tronco na Argentina. O artigo fornece ao leitor uma perspectiva crítica das políticas públicas, seja pela defesa de interesses em torno da promoção comercial de novas tecnologias, seja pela escassez de instrumentos de participação democrática presentes nessa agenda. Esse processo é visto como um desafio para a regulação de temas que envolvem conhecimento especializado em alta tecnologia na América Latina, já que há um embate significativo entre governos, especialistas e agências reguladoras, mediado por poucos elementos técnicos. O texto serve como um excelente estudo de caso para entender como se dá a construção de políticas nacionais de regulação de novas tecnologias em saúde, em um contexto de compreensão limitada dos riscos que envolvem a promoção de novas terapias.

Uma abordagem complementar à discussão apresentada no dossiê é desenvolvida no texto de Sakari Tamminen (University of Helsinki) e Niki Vermeulen (University of Edinburgh), intitulado "Bio-objects: new conjugations of the living". O artigo é uma incursão nos aspectos epistemológicos da investigação da "vida", esta entendida como uma entidade complexa e 
fragmentada pelas novas formas de existir da vida biológica. Nesse sentido, é uma contribuição fundamental que se insere na corrente dos estudos pós-genômicos - campo emergente que reúne concepções de mundo, ideias, discursos e formas de compreensão da vida num empreendimento teórico interdisciplinar. Essa forma híbrida de vida altera profundamente o sistema de relações sociais conforme estávamos acostumados a entender no passado, e introduz novas questões concernentes à governança da vida e da ética. Esse artigo é especialmente relevante para o momento atual, diante das notícias sobre a edição genética de seres humanos - como mostra o caso controverso que se popularizou na mídia internacional em novembro de 2018, do pesquisador chinês He Jiankui, que teria criado bebês geneticamente modificados, com a capacidade de serem resistentes ao vírus $\mathrm{HIV}^{14}$. Os autores desse último artigo do dossiê propõem que o conceito de "bio-objetos" possa ser útil para mapear e analisar as esferas empíricas em que novas conjugações da vida estão sendo rearticuladas.

\section{Considerações finais}

O presente ensaio buscou fornecer ao leitor uma via de interpretação sociológica sobre a dinâmica do conhecimento biomédico e em saúde nas últimas décadas, apresentando alguns elementos introdutórios sobre linhas de investigação e tópicos relevantes dos Estudos Sociais em Ciência e Tecnologia (ESCT). Dessa forma, o texto lança luz para possíveis formas de se estudar os movimentos de natureza política e social ocorridos na esfera da pesquisa nessa área, assim como seus desdobramentos para o conjunto da sociedade. Este artigo, que introduz o presente dossiê, visa direcionar o leitor para a interdisciplinaridade que o tema é capaz de articular, da qual podem resultar novas metodologias e virtuosas agendas de pesquisa sociológica.

Como apresentado ao longo do artigo, essa tem sido uma área de pesquisa de grande interesse por parte das ciências humanas e sociais.

${ }^{14} \mathrm{~A}$ notícia em questão intitula-se "Cientista chinês diz ter criado os primeiros bebês editados geneticamente" e foi publicada na Folha de São Paulo em 26 de novembro de 2018. A notícia está disponível no link https://www1.folha.uol.com.br/ciencia/2018/11/cientistachines-diz-ter-feito-os-primeiros-bebes-editados-geneticamente.shtml. 
Como vimos, desde o final dos anos oitenta essa agenda de pesquisa sociológica tem atingido um número significativo de analistas preocupados em compreender as transformações na dinâmica de produção, uso e circulação do conhecimento biomédico e em saúde humana, com impactos sensíveis nas relações entre o conhecimento, cultura, medicina e sociedade. O potencial desse debate extrapola as fronteiras disciplinares das humanidades e estudar o assunto se tornou um empreendimento interdisciplinar por excelência.

Essa é uma agenda de pesquisa atual, rica e dinâmica que, certamente, pode avançar muito com uma maior contribuição por parte dos cientistas sociais brasileiros. Acredita-se que este dossiê seja capaz de fomentar esse interesse e fornecer instrumentos pertinentes para a análise das novas questões sociais que emergem impulsionadas pelas novas formas de produção, difusão e uso do conhecimento biomédico e de suas tecnologias na sociedade atual.

\section{Agradecimentos}

Os autores agradecem o suporte financeiro da Fundação de Amparo a Pesquisa do Estado de São Paulo (FAPESP), referente aos seguintes processos: n. 2016/20638-8 - "BioNações: a emergência de pesquisas e terapias com células-tronco (Estudo Multi-situado Brasil/Índia)"; n. 2015/24133-5 - "A política científica, tecnológica e de inovação em Saúde no Brasil: o papel do arcabouço político-institucional no desenvolvimento da pesquisa em anticorpos monoclonais"; e n. 2017/18500-0 - "A dinâmica de inovação na indústria biofarmacêutica: novas teorias sobre mudança tecnológica no desenvolvimento de anticorpos monoclonais". Agradecemos também os comentários feitos pelos revisores, que contribuíram muito para aprimorar a versão final do artigo.

Maria Conceição da Costa é Doutora em Ciência Política e Professora Titular do Departamento de Política Científica e Tecnológica, Instituto de Geociências, Universidade Estadual de Campinas, Campinas - SP, Brasil.

”dacosta@ige.unicamp.br

Renan Gonçalves Leonel da Silva é Doutor em Política Científica e Tecnológica e Pósdoutorando (FAPESP) no Departamento de Medicina Preventiva, Faculdade de Medicina, Universidade de São Paulo, São Paulo - SP, Brasil.

”leonnelrg@gmail.com 


\section{Referências}

1. ALBRECHT, Gary L.; FITZPATRICK, Ray; SCRIMSHAW, Susan. Handbook of social studies in health and medicine. Londres: Thousand Oaks e Nova Deli: Sage Publications, 2000.

2. BERGER, Peter L.; LUCKMANN, Thomas. The social construction of reality. A treatise in the sociology of knowledge. Garden City: Doubleday, 1967.

3. BIEHL, João; MORAN-THOMAS, Amy. Symptom: subjectivities, social ills, technologies. Annual Review of Anthropology, n. 38, p. 267-88, 2009.

4. BIEHL, João. Antropologia do devir: psicofármacos - abandono social - desejo. Revista de Antropologia, v. 51, n. 2, p. 413-49, 2008.

5. BIEHL, João; PETRYNA, Adriana. Bodies of rights and therapeutic markets. Social Research, v. 78, n. 2, p. 359-94, 2011.

6. BIJKER, Wiebe. Of bicycles, bakelites and bulbs. Toward a theory of sociotechnical change. Massachusetts: MIT Press, 1995.

7. BORNMANN, Lutz; MUTZ, Rüdiger. Growth rates of modern science: A bibliometric analysis based on the number of publications and cited references. Journal of the Association of the Information Science and Technology, v. 66, n. 11, p. 2215-22, 2015.

8. BOWKER, Geoffrey C.; STAR, Susan L. Sorting things out. Cambridge: The MIT Press, 1999.

9. CALLON, Michel. Society in the making: The Study of technology as a tool for sociological analysis. In: BIJKER, Wiebe et al. Social construction of technological systems. Cambridge: Cambridge University Press, 1987, p. 83-103.

10. CAMARGO JR., Kenneth R. de. A biomedicina. Physis - Revista de Saúde Coletiva [online], v. 15, supl., p. 177-201, 2005.

11. CARVALHO, Sérgio R. et al. Medicalização: uma crítica (im)pertinente? Introdução. Physis - Revista de Saúde Coletiva, Rio de Janeiro, v. 25, n. 4, p. 1251-69, 2015.

12. CHADAREVIAN, Soraya de; KAMMINGA, Harmke. Molecularizing biology and medicine: new practices and alliances 1910s-1970s. Amsterdã: Harwood Academic Publishers, 1998.

13. CLARKE, Adele E. et al. Biomedicalization: Technoscientific transformations of health, illness, and U.S. biomedicine. American Sociological Review, v. 68, p. 161-94, abr. 2003.

14. CONRAD, Peter. The Medicalization of society. Baltimore: The Johns Hopkins University Press, 2007.

15. DAYHOFF, Margaret O. et al. Atlas of protein sequence and structure. Silver Spring: National Biomedical Research Foundation, 1965. 
16. ECKS, Stefan. Pharmaceutical citizenship: antidepressant marketing and the promise of demarginalization in India. Anthropology \& Medicine, v. 12, n. 3, p. 239-54, 2005.

17. ETZKOWITZ, Henry; LEYDESDORFF, Loet. The dynamics of innovation: from national systems and "Mode 2 " to a Triple Helix of university-industry-government relations. Research Policy, v. 29, n. 2, p. 109-23, 2000.

18. FAGOT-LARGEAULT, Anne. Embriões, células-tronco e terapias celulares: questões filosóficas e antropológicas. Estudos Avançados, v. 18, n. 51, p. 227-45, 2004.

19. FISCHER, Michael M. J. Anthropological Futures. Durham: Duke University Press, 2009.

20. FOX-KELLER, Evelyn. The century of the gene. Cambridge: Harvard University Press, 2002.

21. FREEMAN Chris. The National system of innovation in historical perspective. Cambridge Journal of Economics, v. 19, n. 1, p. 5-24, 1995.

22. GAYARD, Nicole. A cooperação sul-sul em saúde brasileira: considerando conhecimentos, imaginários e práticas de uma política internacional. 206p. Tese (Doutorado em Política Científica e Tecnológica) - Instituto de Geociências, Universidade Estadual de Campinas, Campinas - SP, 2016.

23. GIBBON, Sahra et al. Handbook of genomics, health and society, 2. ed. Nova York: Routledge International Handbooks, 2018.

24. GIBBONS, Michael et al. The New production of knowledge. Londres: Sage Publications, 1994.

25. HAJER, Maarten. Authoritative governance: policy making in the age of mediatization. Oxford: Oxford University Press. 2009.

26. HESS, David J. Science studies: an advanced introduction. Nova York: NYU Press, 2012.

27. HILGARTNER, Stephen. Reordering life: knowledge and control in the genomics revolution. Cambridge: MIT Press, 2017.

28. HURLEY, Dan. Why are so few blockbusters drugs invented today? The New York Times Magazine, 13 nov. 2014. Disponível em: <https://www.nytimes. com/2014/11/16/magazine/why-are-there-so-few-new-drugs-invented-today. html>.

29. JASANOFF, Sheila. Future imperfect: science, technology, and the imaginations of modernity. In: JASANOFF, Sheila.; KIM, Sang-Hyun. Dreamscapes of modernity: sociotechnical imaginaries and the fabrication of power. Chicago: The University of Chicago Press, 2015. p. 1-33.

30. JASANOFF, Sheila. The idiom of co-production. In: JASANOFF, Sheila. States of knowledge: the co-production of science and the social order. Londres e Nova York: Routledge, 2004. 
31. JASANOFF, Sheila; KIM, Sang-Hyun. Dreamscapes of modernity: sociotechnical imaginaries and the fabrication of power. Chicago: The University of Chicago Press, 2015.

32. JENKINS, Janis H. (Ed.). Pharmaceutical self: the global shaping of experience in an age of psychopharmacology. Santa Fé: School for Advanced Research Press, 2011.

33. KEATING, Peter; CAMBRÓSIO, Alberto. Biomedical platforms: realigning the normal and the pathological in late-twentieth-century medicine. Cambridge: MIT Press, 2006.

34. LATOUR, Bruno; WOOLGAR, Steve. Laboratory life: the construction of scientific facts. Princeton: Princeton University Press, 1979.

35. LEACH, Melissa; SCOONES, Ian. Carbon conflicts and forest landscapes in Africa. Londres: Routledge, 2015.

36. LOCK, Margaret. Encounters with aging. Mythologies of menopause in Japan and North America. Oakland: University of California Press, 1995.

37. LOCK, Margaret; NGUYEN, Vinh-Kim. An anthropology of biomedicine. Oxford: Wiley-Blackwell, 2010.

38. LÖWY, Ilana; GAUDILLIÈRE, Jean-Paul. Localizing the global: testing for hereditary risks of breast cancer. Science, Technology $\&$ Human Values, v. 33, n. 3, maio, p. 299-325, 2008.

39. LUHRMANN, Tanya. God as the ground of empathy. Anthropology Today, v. 16, n. 1, 2002.

40. MALNIC, Gerhard. O apoio à pesquisa na área biomédica básica. Revista USP, São Paulo, n. 73, p. 32-9, 2007.

41. MERTON, Robert K. The normative structure of science. In: MERTON, R. K. The Sociology of science: theoretical and empirical investigations. Chicago: University of Chicago Press, [1942] 1973, p. 267-80.

42. MITTRA, James. The new health bioeconomy: R\&D policy and innovation for the twenty-first century. Basinstoke: Palgrave Macmillan, 2016.

43. MOSES, Hamilton et al. The anatomy of medical research: US and international comparisons. JAMA, v. 313, n. 2, p. 174-89, 2015.

44. MOWERY, David C. The changing structure of the U. S. national innovation system: implications for international conflict and cooperation in R\&D policy. Research Policy, v. 27, p. 639-54, 1998.

45. NATIONAL SCIENCE FOUNDATION. Science: the endless frontier: a report to the President by Vannevar Bush, Director of the Office of Scientific Research and Development, jul. 1945. Disponível em: < https://www.nsf.gov/od/lpa/nsf50/ vbush1945.htm>.

46. NATURE. Initial Sequencing and analysis of human genome. Nature, v. 409, n. 15, p. 860-921, fev. 2001. https://doi.org/10.1038/35057062. 
47. NELSON, Alondra. The social life of DNA: race, reparation and conciliation after the genome. Boston: Beacon Press, 2016.

48. NICHOLSON, Linda. Feminism/Postmodernism. Nova York: Routledge, 1990.

49. NOWOTNY, Helga; SCOTT, Peter; GIBBONS, M. Re-thinking science. Knowledge and the public in an age of uncertainty. Cambridge: Polity Press, 2001.

50. NUNES, Everardo D. A sociologia da saúde no Brasil - a construção de uma identidade. Ciência \& Saúde Coletiva [online], v. 19, n. 4, p. 1041-52, 2014.

51. OECD. OECD Science, technology and innovation outlook 2016. Paris: OECD Publishing, 2016. Disponível em: < https://doi.org/10.1787/sti_in_outlook2016-en>.

52. OSTHUS, Rebecca; BENOS, Dale. Making a case for NIH funding: how cures are built on decades of research. The Physiologist, n. 49, p. 313-21, 2006.

53. OWENS, Brian. Mapping biomedical research in the USA. The Lancet, v. 384, n. 9937, p. 11-4, 2014.

54. PARSONS, Talcott. The social system. Londres: Routledge, 1951.

55. PETRYNA, Adriana; LAKOFF, Andrew; KLEINMAN, Arthur. Global pharmaceuticals: ethics, markets, practices. Durham, NC: Duke University Press, 2006.

56. ROSE, Nikolas. The politics of life itself: biomedicine, power, and subjectivity in the twenty-first century. Princeton: Princeton University Press, 2007.

57. SILVA, Renan G. L. da; COSTA, Maria C. da. A emergência da biologia molecular no estado de São Paulo (1952-1970). Revista Tecnologia e Sociedade, v. 14, n. 31, p. 1-27, maio/ago. 2018.

58. SILVA, Renan G. L. da; NOVAES, Hillegonda M. D. Understanding the political framework of biopharmaceutical development in Brazil: the case of monoclonal antibodies. Proceedings of the 23rd International Conference on Science and Technology Indicators STI 2018, p. 566-75. Centre for Science and Technology Leiden University, Países Baixos, 2018.

59. SOLLA PRICE, Derek. Little science, big science. Nova York: Columbia University Press, 1963.

60. SPIESS, Maiko; COSTA, Maria C. da. Medicina, saúde e doença: antecedentes e oportunidades para expansão temática e teórica dos estudos CTS. In: KREIMER, Pablo et al. (Orgs) Perspectivas latinoamericanas en el estudio social de la ciencia, la tecnología y la sociedad. Buenos Aires: Siglo XXI Editoras, 2014, p 44-54.

61. STRASSER, Bruno. Institutionalizing molecular biology in post-war Europe: a comparative study. Studies in history and philosophy of biological \& biomedical sciences, v. 33, n. 3, p. 515-46, 2002. 
62. STRASSER, Bruno. Collecting, comparing, and computing sequences: the making of Margaret O. Dayhoff's Atlas of protein sequence and structure, 19541965. Journal of the History of Biology, v. 43, n. 4, p. 623-60, 2010.

63. VELHO, Lea. Modos de produção de conhecimento e inovação: estado da arte e implicações para a política científica, tecnológica e de inovação. Projeto Nova Geração de Políticas de Ciência, Tecnologia e Inovação. Nota técnica. Brasília: Centro de Gestão e Estudos Estratégicos, 2010. Disponível em: <https://www.cgee.org.br/documents/10195/734063/NT_LeaVelho_Final_6328. pdf/8b7f0c8a-3bf0-48f9-a3b5-2abf62feffb4?version $=1.0>$.

64. ZORZANELLI, Rafaela T.; CRUZ, Murilo G. A. O conceito de medicalização em Michel Foucault na década de 70. Interface (Comunicação, Saúde, Educação), v. 22. n. 66, p. 721-31, 2018. 